\title{
Sistem Pemetaan Udara Menggunakan Pesawat Fixed Wing
}

\author{
Muliady ${ }^{1}$, Ezra Julio Subagya ${ }^{1}$
}

\begin{abstract}
Generally aerial mapping mission is a high cost operation and require an aircraft that must be controlled by a reliable pilot. In an effort to solve the problem. Unmanned Aerial Vehicle (UAV) technology becomes one of the solutions, due to consideration of operational costs, accident risk, and flight preparation time.

This research shows an aerial mapping system using a fixed wing glider plane characteristics UAV built from polyfoam, balsa wood, and carbon fiber. The shape of the wing airfoil is flat-bottomed and the wing's position is top wing. The UAV motion controllers are ailerons, elevators, rudders driven by servo motors. Use the flight controller to allow aircraft to fly automatically. The altitude, speed, and position of the aircraft can be monitored via telemetry connected to the flight controller and a laptop. The aerial mapping method implemented is photogrammetric. The UAV will fly to the area to be mapped and do a sequential photo shoot until the entire area is covered. All photo data will be processed to become a territorial map. Using mission planner software for UAV programming and PIX4D software for image data processing. The UAV has been tested to air automatically following the programmed lanes. The flight controller can trigger the camera automatically at the pre-programmed position. Testing of map quality results was obtained by experimental flight of $100 \mathrm{~m}, 125 \mathrm{~m}$, and $150 \mathrm{~m}$ with a cruising speed of $12 \mathrm{~m} / \mathrm{s}$. The best map result is from a height of $100 \mathrm{~m}$ with a cruising speed of $12 \mathrm{~m} / \mathrm{s}$ aircraft.
\end{abstract}

KEYWORDS: Aerial mapping system, UAV fixed wing, PIX4D

\begin{abstract}
ABSTRAK: Umumnya misi pemetaan udara memerlukan biaya operasional yang tinggi dan pesawat terbang yang harus dikendalikan oleh pilot yang andal. Dalam upaya menyelesaikan masalah, teknologi Unmanned Aerial Vehicle (UAV) menjadi salah satu solusi, karena pertimbangan biaya operasional, risiko kecelakaan, dan waktu persiapan penerbangan. Penelitian ini menunjukkan sistem pemetaan udara menggunakan pesawat fixed wing $U A V$ berkarakteristik glider yang dibangun dari polyfoam, kayu balsa, dan serat karbon. Bentuk airfoil sayap datar-bottomed dan posisi sayap adalah sayap atas. Kontrol gerak UAV adalah ailerons, elevator, kemudi yang didorong oleh motor servo. Gunakan pengontrol penerbangan untuk memungkinkan pesawat terbang secara otomatis. Ketinggian, kecepatan, dan posisi pesawat dapat dipantau melalui telemetri yang terhubung ke pengontrol penerbangan dan laptop. Metode pemetaan udara yang diterapkan adalah fotogrametri. UAV akan terbang ke area yang akan dipetakan dan melakukan pemotretan berurutan hingga seluruh area tertutup. Semua data foto akan diproses menjadi peta teritorial. Menggunakan perangkat lunak perencana misi untuk pemrograman UAV dan perangkat lunak PIX4D untuk pemrosesan data gambar. UAV telah diuji untuk mengudara secara otomatis mengikuti jalur terprogram. Pengontrol penerbangan dapat memicu kamera secara otomatis pada posisi yang diprogram sebelumnya. Pengujian hasil kualitas peta diperoleh dengan penerbangan eksperimental 100m, $125 \mathrm{~m}$, dan $150 \mathrm{~m}$ dengan kecepatan jelajah $12 \mathrm{~m} / \mathrm{s}$. Hasil peta terbaik adalah dari ketinggian $100 \mathrm{~m}$ dengan kecepatan jelajah $12 \mathrm{~m} / \mathrm{s}$ pesawat.
\end{abstract}

KATA KUNCI: Sistem Pemetaan Udara, UAV fixed wing, Pix $4 D$

\section{PENDAHULUAN}

$\mathrm{P}$ enelitian UAV (Unmanned Aerial Vehicle) tidak hanya dilakukan oleh militer saja, tetapi juga oleh badan-badan riset, dan perguruan tinggi, sedangkan aplikasinya banyak digunakan pada dunia industri, hiburan dan bidang sipil. Dengan teknologi $U A V$, kerja manusia dapat digantikan antara lain dalam hal pemetaan (mapping), pemantauan (monitoring), pemadaman api, penyelamatan, dan pengiriman barang. Penggunaan $U A V$ pada mapping dibutuhkan untuk survei lahan pembangunan, meneliti permukaan tanah untuk keperluan pertambangan, mengambil foto dan video untuk pembuatan film, dan dalam militer digunakan untuk memantau wilayah perbatasan negara. UAV menjadi salah satu alternatif yang paling efektif dalam melakukan misi mapping tersebut, karena waktu persiapan yang lebih singkat, biaya relatif lebih murah, dan pesawat tersebut tidak memerlukan tenaga pilot untuk menerbangkannya.

Pada penelitian ini digunakan pemetaan dengan metode fotogrametri, yang didefinisikan sebagai seni, sains, dan teknologi untuk mendapatkan informasi yang dapat dipercaya tentang benda fisik dan lingkungan melalui proses pencatatan, pengukuran, dan penafsiran gambar. Fotogrametri dibagi menjadi fotogrametri udara dan fotogrametri terestrial. Fotogrametri udara dilakukan dengan menggunakan pesawat udara yang membawa kamera untuk melakukan foto udara dan biasanya metode ini dipakai untuk pemetaan daerah yang luas dan biayanya lebih murah dibanding fotogrametri terrestrial[1].

Faktor-faktor penentu keberhasilan dalam pemetaan tergantung pada kemampuan terbang $U A V$, perencanaan jalur terbang, dan pengaturan pengambilan foto udara terutama tinggi terbang, overlap, dan sidelap saat pengambilan foto. Pada penelitian ini ditunjukkan parameter-parameter sistem pemetaaan udara dengan menggunakan pesawat fixed wing untuk dapat menghasilkan pemetaan udara.

\section{PERANGKAT UTAMA SISTEM PEMETAAN UDARA}

Komponen utama $U A V$ adalah flight controller yang berfungsi mengontrol manuver terbang $U A V$. Dalam flight controller terdapat beberapa sensor utama, yaitu accelerometer, gyroscope, dan barometer. Sensor accelerometer berfungsi untuk mengukur percepatan suatu objek. Sensor gyroscope berfungsi untuk mengukur atau mempertahankan orientasi dengan prinsip ketetapan momentum sudut. Sensor accelerometer dan gyroscope

\footnotetext{
${ }^{1}$ Program Studi Teknik Elektro, Universitas Kristen Maranatha
} 
adalah sensor untuk keseimbangan. Barometer berfungsi untuk mendeteksi adanya perubahan ketinggian. Cara kerja barometer dalam mengukur ketinggian adalah dengan cara mendeteksi tekanan udara relatif di sekitarnya. Jika tekanan udara naik berarti ketinggian berkurang, jika tekanan udara berkurang berarti ketinggian bertambah.

Flight controller APM 2.7 yang digunakan memiliki 8 port input dan 8 port output. Telemetry port digunakan untuk modul telemetry yang terhubung secara wireless pada telemetry ground control station. I2C port untuk menghubungkan dengan sensor tambahan jika diperlukan. Gambar 1 menunjukkan port pada flight controller APM 2.7.

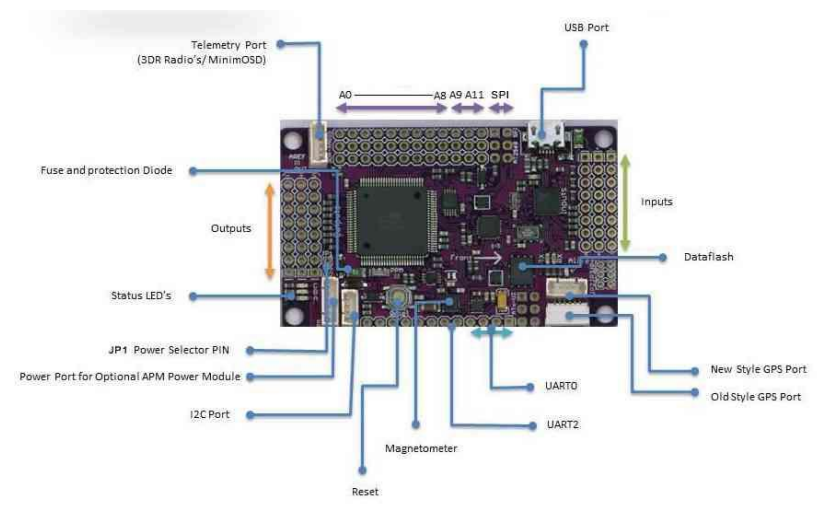

- Gambar 1 Keterangan Fungsi Port APM 2.7

Pada Gambar 2 ditunjukan 8 port input, yaitu channel-1 kontrol roll, channel-2 kontrol elevator, channel3 kontrol throttle, channel-4 kontrol yaw, channel-5 kontrol mode terbang pesawat. Port input akan dihubungkan ke receiver remote control.

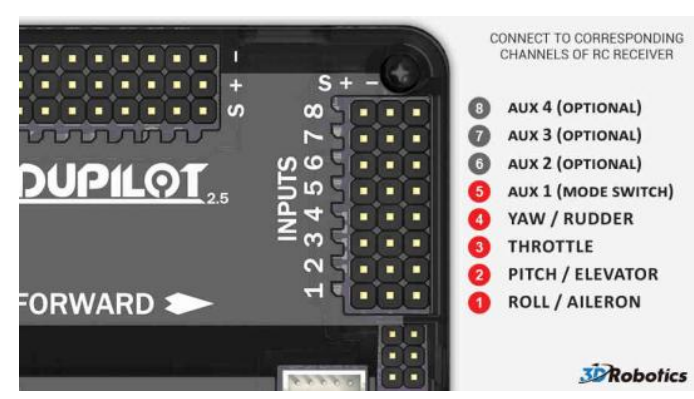

- Gambar 2 Keterangan Port Input APM

CHDK(Canon Hack Development Kit) adalah alat pengembangan eksperimental, yang secara sementara dapat membuat kamera Canon bisa dikontrol dengan menggunakan skrip. Fungsi dari skripnya bisa memotret, mengontrol zoom kamera, mengatur fokus, dan mengakses banyak fitur kamera lainnya. Namun, pada penelitian ini penggunaan skrip tersebut hanya untuk pengontrolan shutter kamera melalui port USB. Skrip tersebut dapat membuat fungsi port USB menjadi input trigger dari flight controller.

Seperti pada Gambar 3 adalah contoh instalasi kabel antara flight controller APM dengan kamera canon SX260 HS. Ketika CHDK sudah di instalasi ke dalam kamera canon tersebut maka kamera akan bisa mendeteksi setiap input yang berasal dari flight controller APM. Dan dalam hal ini, kamera khusus diatur agar bisa menerima perintah trigger kamera[2].

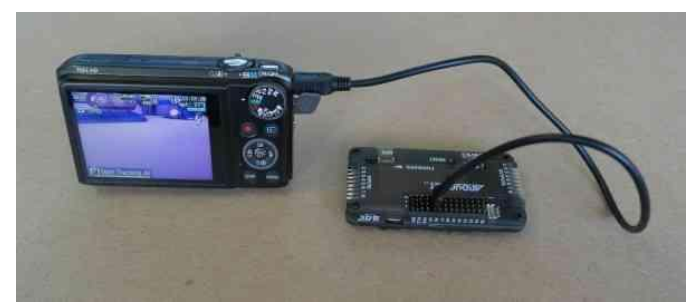

- Gambar 3 Koneksi APM pada Kamera Canon SX260 HS dengan Kabel Trigger 
Pix4D adalah perangkat lunak aplikasi komputer yang salah satu fungsinya adalah untuk memproses hasil gambar - gambar yang memiliki informasi GPS (geolocation) maupun yang tidak memiliki geolocation menjadi sebuah satu - kesatuan gambar 2D. Dalam penggunaan Pix4D, ada beberapa syarat yang disarankan untuk dipenuhi agar menghasilkan hasil yang maksimal sesuai dengan standard Pix4D. Pix4D manual menyarankan untuk memprogram pemetaan udara dengan setidaknya $75 \%$ overlap dan $60 \%$ sidelap [3].

Untuk pembuatan lajur terbang pesawat disarankan seperti pada Gambar 4, titik - titik merah tersebut adalah posisi kamera mengambil foto udara dan garis hitam yang sejalur pada titik - titik merah tersebut adalah lajur terbang pesawat.

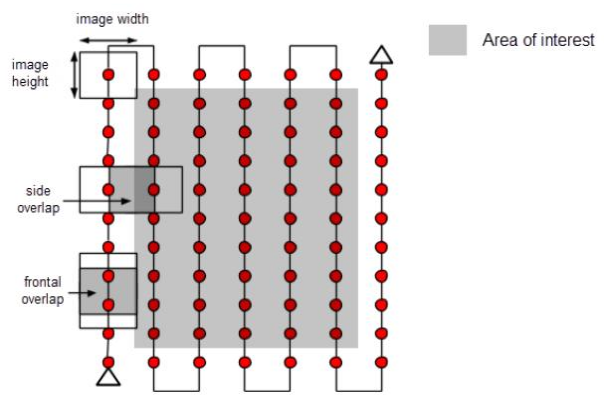

- Gambar 4 Perencanaan Lajur Terbang Menurut Standard Manual Pix4D

Dalam pemetaan yang pengambilan foto udaranya melebihi ketinggian 50m, disarankan untuk menggunakan perpective lens dengan focal length antara $22 \mathrm{~mm}-80 \mathrm{~mm}$ (in $35 \mathrm{~mm}$ equivalent). Untuk pemetaan indoor atau daerah yang kecil atau dekat disarankan untuk menggunakan lensa fisheye atau lensa dengan focal length yang sangat kecil. Pix4D dapat memproses gambar yang memiliki geolocation maupun yang tidak memiliki geolocation. Setidaknya $80 \%$ dari keseluruhan gambar yang akan diproses memiliki geolocation untuk hasil yang baik dan pemrosesan gambar yang cepat.

Ada 3 tahap proses dalam Pix4d sebelum gambar menjadi layout peta, yaitu:

1. Initial Processing:

Secara otomatis mengekstrak titik kunci dari gambar untuk menghitung parameter kamera internal dan eksternal menggunakan perangkat lunak yang canggih. Automatic Aerial Triangulation (AAT) dan Bundle Block Adjustment (BBA).

2. Point Cloud dan Mesh:

Menghasilkan awan titik 3D yang padat dan jala bertekstur 3D.

3. DSM, Orthomosaic and Index:

Menghasilkan peta DSM, orthomosaic, reflectance dan indeks.

\section{SISTEM PEMETAAN UDARA}

Pada ground control station telah diprogram terlebih dahulu rencana terbang UAV, termasuk pengaturan pola, arah, kecepatan, dan tinggi terbang, saaat pelaksanaan misi. UAV akan terbang ke daerah yang akan dipetakan dan flight controller akan memicu kamera tepat di titik waypoint yang sudah diprogram. Foto yang sudah diambil oleh kamera akan disimpan di dalam memory card[4]. Setelah UAV mendarat, foto akan dipindahkan ke dalam komputer. Flight controller sudah diatur untuk merekam koordinat tepat pada saat kamera dipicu, hasil rekam jejak tersebut dikenal dengan nama Log-bitmask dalam perangkat lunak mission planner. Hasil rekam log-bitmask tersebut akan diunduh dan digabungkan dengan hasil foto kamera, dengan begitu semua foto akan memiliki informasi koordinat berupa longitude, latitude, dan altitude. Gambar geotagged tersebut selanjutnya diproses oleh perangkat lunak Pix4D yang hasil output-nya berupa peta 2 dimensi. Dapat dilihat pada Gambar 5. 

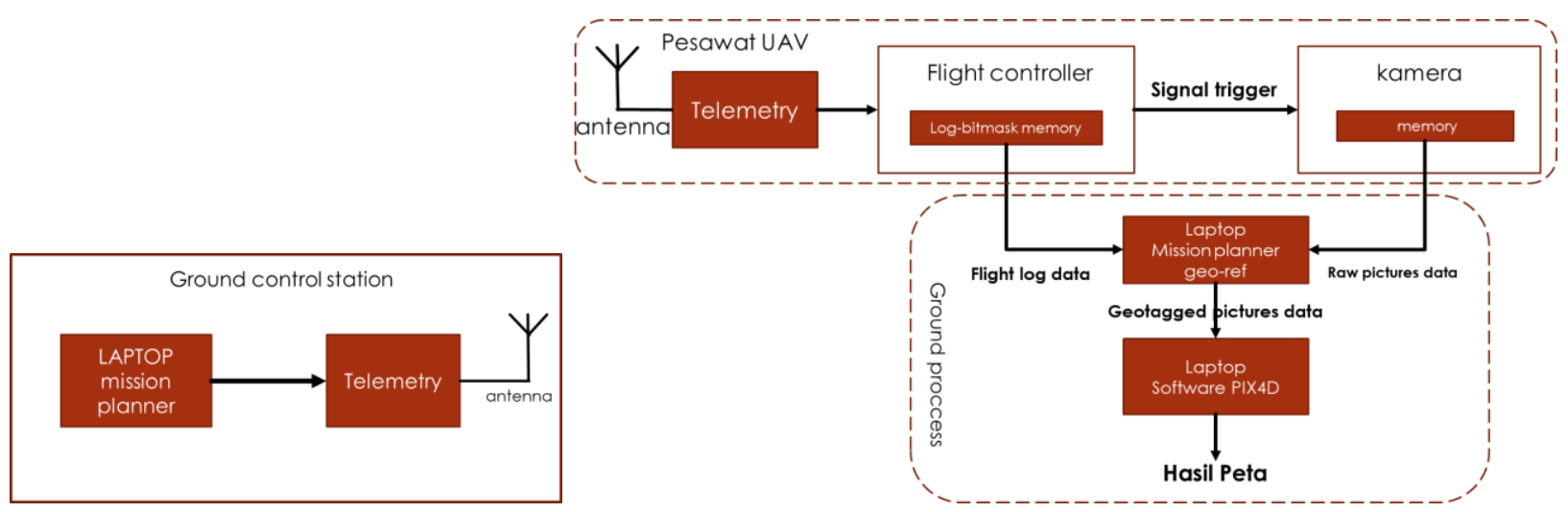

- Gambar 5 Diagram Sistem Pemetaan Udara

\section{Pesawat Udara Tanpa Awak}

Dalam pemetaan udara untuk suatu wilayah diperlukan pesawat UAV yang stabil dan efisien ketika mengudara. Kestabilan dan efesiensi pesawat ditentukan oleh banyak parameter, antara lain: power loading dan wing loading. Dalam dua hal tersebut menyangkut masalah desain dari luas sayap berbanding dengan beratnya dan juga dari beratnya berbanding dengan power motor elektrik DC. Power loading akan menghasilkan perhitungan estimasi daya motor elektrik minimal yang dibutuhkan agar pesawat memiliki thrust yang mencukupi[5]. Nilai wing loading dapat menghasilkan perhitungan untuk menentukan luas sayap yang akan direalisasikan. Pertama diketahui nilai wing loading dan berat total dari pesawat seperti pada Tabel I, lalu berat total pesawat dibagi dengan nilai wing loading maka akan diketahui luas sayap yang harus direalisasikan[6]. Aspect ratio sayap pesawat akan menentukan dimensi panjang dan lebar nya sayap. Dimensi fuselage, stabilizer area, dan fin area akan mengacu pada dimensi sayap utama pesawat. Gambar 6 dan Gambar 7 menunjukkan desain ukuran pesawat, dan Gambar 8 hasil realisasi desain pesawat.

Selain dari segi fisik pesawat juga ada faktor dari sistem elektronik pesawat. Pesawat akan terbang secara otomatis dengan bantuan flight controller. Flight controller akan diprogram dengan program mission planner yang memiliki banyak parameter yang harus di setting[7]. Jadi secara keseluruhan sistem hardware dan software yang dirancang dan direalisasikan akan menghasilkan suatu pesawat UAV yang memiliki kemampuan pemetaan secara otomatis.

Tabel 1. Perkiraan Berat Total Pesawat

\begin{tabular}{|l|l|l|}
\hline No & Perangkat & Berat (gram) \\
\hline 1 & Kamera + baterai & 207 \\
\hline 2 & Kamera Mobius FPV & 41 \\
\hline 3 & 4 bh motor servo & 27 x 4=108 \\
\hline 4 & ESC & 60 \\
\hline 5 & Power Module & 27 \\
\hline 6 & Flight controller + GPS & 62 \\
\hline 7 & Telemetry & 20 \\
\hline 8 & Receiver & 13 \\
\hline 9 & Kabel konektor & 28 \\
\hline 10 & Baterai lipo + lipo checker & 195 \\
\hline 11 & Propeller + adapter & 17 \\
\hline 12 & Motor brushless elektrik & 80 \\
\hline 13 & $\begin{array}{l}\text { Depron untuk bagian sayap utama, fuselage, } \\
\text { sayap vertikal, sayap horizontal, }\end{array}$ & 319 \\
\hline 14 & Kayu balsa dudukan motor elektrik & 148 \\
\hline 15 & Tali perekat sayap & 12 \\
\hline 16 & $\begin{array}{l}\text { Perkiraan material perekat (lem tembak, solasi, } \\
\text { double tape) }\end{array}$ & \pm 150 \\
\hline
\end{tabular}




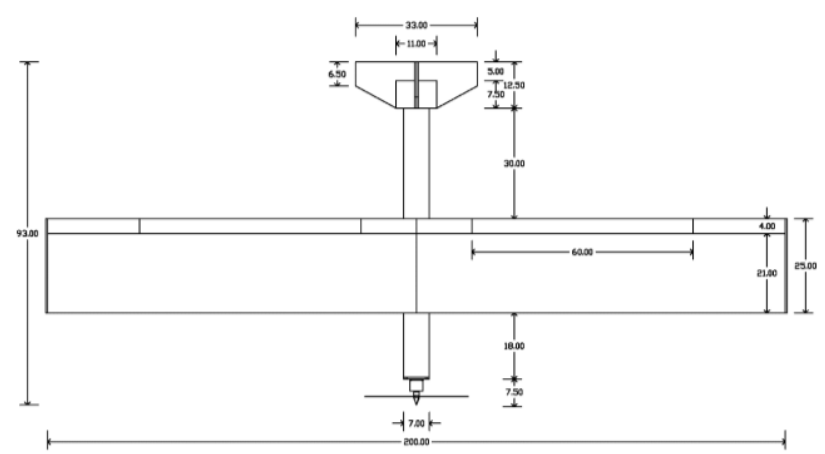

- Gambar 6 Perancangan Dimensi Pesawat Tampak Atas

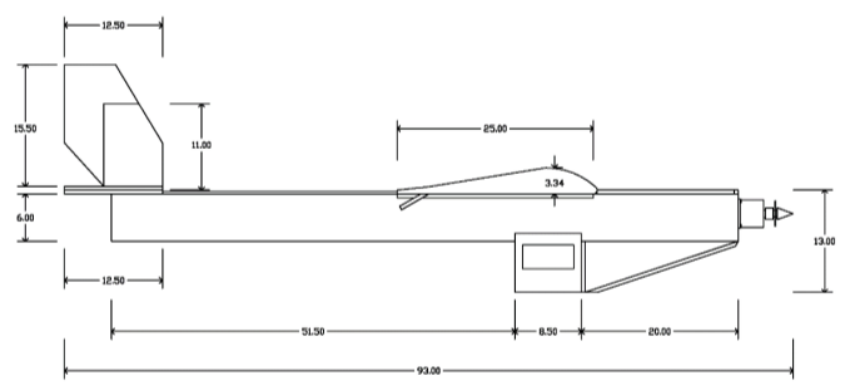

ש Gambar 7 Perancangan Dimensi Pesawat Tampak Samping

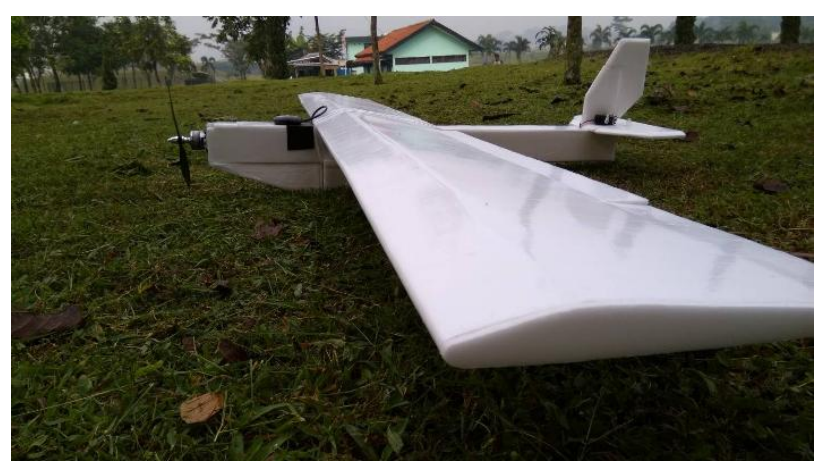

Gambar 8 Realisasi Pesawat Tampak Samping

Flight controller adalah komponen yang berfungsi untuk mendeteksi setiap gerak pesawat, menerima perintah kendali dari receiver maupun telemetry, dan memberikan output sinyal kontrol pada setiap komponen yang terhubung. Remote control terhubung secara wireless dengan receiver. Remote control memiliki 5-channel pengontrolan, yaitu 2 servo aileron di ch-1, 1 servo elevator di ch-2, 1 pengontrol motor elektrik di ch-3, 1 servo rudder di ch-4, dan ch-5 untuk pengontrolan mode pesawat. Mode pesawat terbagi menjadi 5 jenis, yaitu manual mode, stabilize mode, return to launge mode, aututune mode, dan auto mode. Dalam realisasi pesawat, flight controller mengontrol servo aileron 1, servo aileron 2, servo rudder, servo elevator, ESC, dan trigger kamera. Ketika flight controller perlu melakukan manuver maka keempat servo akan bergerak mengendalikan pesawat sesuai dengan perintah yang sudah diterima. GPS sudah terintegrasi dengan flight controller yang berfungsi sebagai penuntun arah dan penuntun ketinggian jelajah pesawat. Kamera canon A1000 yang digunakan dalam pemetaan udara akan ditrigger oleh flight controller ketika pesawat sudah dalam posisi koordinat yang sudah ditentukan. Kecepatan jelajah pesawat ditentukan oleh kecepatan brushless electric motor yang kecepatannya dikendalikan oleh ESC, dan ESC tersebut juga secara langsung mendapat sinyal kontrol dari flight controller. Power module yang dipasang berfungsi sebagai distribusi power untuk menyalakan flight controller dan motor. Berikut adalah diagram blok perancangan dan realisasi dari sistem kontrol pesawat udara ditunjukkan pada Gambar 9. 


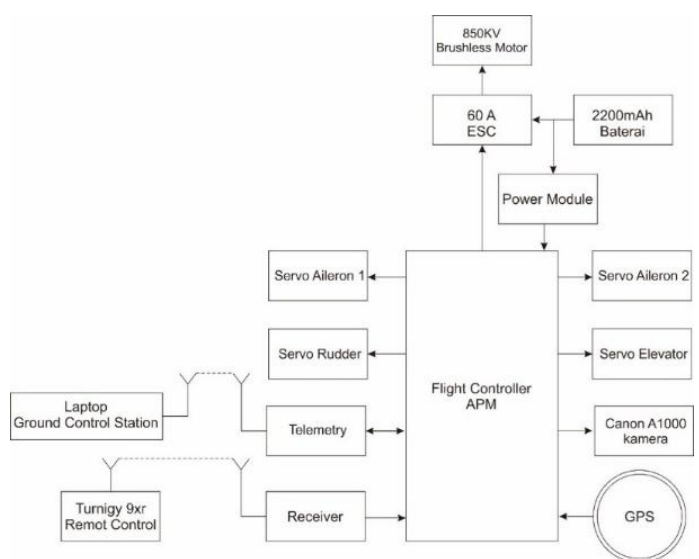

\section{Proses Tuning}

- Gambar 9 Integrasi Sistem Kontrol Pesawat

Sebelum memulai proses pemetaan, pesawat udara tanpa awak harus melalui proses tuning untuk mengatur keseimbangan pesawat saat mengudara. Proses tuning tersebut dilakukan secara manual dan otomatis. Pertama, pesawat harus bisa mengudara secara full manual, pesawat harus dapat dikendalikan terlebih dahulu oleh pilot meskipun terbang tanpa menggunakan flight controller. Setelah memenuhi kriteria tersebut, pesawat diterbangkan secara manual dan ketika sudah dapat mengudara dalam kondisi lurus, mode pesawat akan diubah menjadi mode stabilize. Dalam mode stabilize tersebut, pesawat akan digerakan bermanuver dan melihat kemampuan flight controller untuk menyeimbangkan kembali pesawat tersebut dalam kondisi semula. Kemampuan flight controller dalam proses penyeimbangan pesawat sangat berpengaruh dengan besarnya nilai PID pesawat. Oleh karena itu dalam tuning manual, nilai PID yang didapat adalah dengan cara trial and error. Setelah didapat nilai PID yang terbaik dari tuning manual, pesawat akan mendarat dan akan mengudara kembali untuk melalukan tuning otomatis. Dalam tuning otomatis, pesawat akan terbang dalam mode autotune. Mode autotune akan membuat terbang pesawat bermanuver secara otomatis dan mengkalkulasi nilai PID secara otomatis. Berikut pembahasan tuning manual dan otomatis PID:

\section{Tuning Manual}

Proses tuning nilai PID terdiri dari 5 tahap trial and error. Pertama pesawat diterbangkan secara manual dan ketika terbang lurus mode pesawat diubah menjadi stabilize, yaitu ketika flight controller mengontrol stabilisasi pesawat. Dalam kondisi tersebut pesawat digerakan roll, pitch, dan yaw kekiri, kanan, atas, dan bawah. Flight kontroller akan mengontrol posisi pesawat dalam keadaan semula. Berikut pada Tabel II adalah hasil nilai PID yang berubah. Pada Tabel III dijelaskan hasil pengontrolan pesawat berdasarkan nilai pada Tabel II.

Tabel 2 Nilai PID Hasil Tuning Manual

\begin{tabular}{|l|l|l|l|l|l|l|l|l|l|}
\hline \multicolumn{9}{|c|}{ Roll } & \multicolumn{3}{c|}{ Pitch } & \multicolumn{3}{c|}{ Yaw } \\
\hline \multirow{2}{*}{ DATA } & \multicolumn{3}{|c|}{ Panual Tuning } \\
\cline { 2 - 10 } & $\mathrm{P}$ & $\mathrm{I}$ & $\mathrm{D}$ & $\mathrm{P}$ & $\mathrm{I}$ & $\mathrm{D}$ & $\mathrm{P}$ & $\mathrm{I}$ & $\mathrm{D}$ \\
\hline 1 & 1.80 & 0.00 & 0.00 & 1.80 & 0.00 & 0.00 & 1.00 & 0.00 & 0.00 \\
\hline 2 & 1.50 & 0.00 & 0.00 & 1.50 & 0.00 & 0.00 & 1.00 & 0.00 & 0.00 \\
\hline 3 & 1.20 & 0.00 & 0.00 & 1.20 & 0.00 & 0.00 & 1.00 & 0.00 & 0.00 \\
\hline 4 & 0.90 & 0.00 & 0.00 & 0.50 & 0.00 & 0.00 & 1.00 & 0.00 & 0.00 \\
\hline 5 & 0.80 & 0.00 & 0.00 & 0.20 & 0.00 & 0.00 & 1.00 & 0.00 & 0.00 \\
\hline
\end{tabular}

Tabel 3. Hasil Karakateristik Terbang

\begin{tabular}{|l|l|}
\hline & \multicolumn{1}{|c|}{ HASIL KARAKTERISTIK TERBANG } \\
\hline Data 1 & $\begin{array}{l}\text { Pesawat dapat mengudara dengan baik akan tetapi jika aileron dan elevator digerakan, } \\
\text { pengkoreksian dari flight controller masih terlalu besar dan sensitif terhadap errornya sehingga }\end{array}$ \\
\hline
\end{tabular}




\begin{tabular}{|l|l|}
\hline & $\begin{array}{l}\text { membuat gerak pesawat berosilasi terus menerus; membuat gerak pesawat bergerak naik turun } \\
\text { dan roll kiri kanan menjadi tidak stabil }\end{array}$ \\
\hline Data 2 & $\begin{array}{l}\text { Pengkoreksian dari flight controller masih terlalu besar dan sensitif terhadap errornya, hasil } \\
\text { terbang masih berosilasi terus menerus }\end{array}$ \\
\hline Data 3 & $\begin{array}{l}\text { Pengkoreksian dari flight controller masih terlalu besar dan berosilasi cukup lama namun osilasi } \\
\text { tersebut berkurang dan kembali stabil }\end{array}$ \\
\hline Data 4 & $\begin{array}{l}\text { Pengkoreksian dari flight controller sangat responsif tetapi lebih bertahap, namun osilasi masih } \\
\text { perlu diredam karena koreksi masih terlalu lama }\end{array}$ \\
\hline Data 5 & $\begin{array}{l}\text { Pengkoreksian dari flight controller cukup responsif tapi bertahap dengan osilasi yang sangat } \\
\text { sedikit }\end{array}$ \\
\hline
\end{tabular}

\section{Tuning PID Ototmatis}

Ada 3 perubahan nilai PID yang direkam seperti ditunjukan pada Tabel IV. Ketika sedang dilakukan autotuning angin berpengaruh terhadap nilai PID. Kecepatan angin ketika autotune $1.25 \mathrm{~m} / \mathrm{s}$. Pesawat hanya melakukan sekali autotuning. Pertama pesawat diterbangkan dalam mode manual dan ketika pesawat sudah dalam posisi terbang lurus diubah ke dalam mode autotune. Pesawat akan secara otomatis mengubah nilai PID.

Tabel 4. Nilai PID Hasil Tuning Otomatis

\begin{tabular}{|l|c|c|c|l|l|l|c|c|c|}
\hline \multicolumn{10}{|c|}{ PID Autotune } \\
\hline & \multicolumn{3}{|c|}{ Roll } & \multicolumn{4}{c|}{ Pitch } & \multicolumn{3}{c|}{ Yaw } \\
\cline { 2 - 10 } & $\mathrm{P}$ & $\mathrm{I}$ & $\mathrm{D}$ & \multicolumn{1}{|c|}{$\mathrm{P}$} & $\mathrm{I}$ & $\mathrm{D}$ & $\mathrm{P}$ & $\mathrm{I}$ & $\mathrm{D}$ \\
\hline Nilai 1 & 0.80 & 0.00 & 0.00 & 0.20 & 0.00 & 0.000 & 1.00 & 0.00 & 0.00 \\
\hline Nilai 2 & 0.80 & 0.056 & 0.056 & 0.231525 & 0.0147 & 0.01620675 & 1.00 & 0.00 & 0.00 \\
\hline Nilai & 0.80 & 0.056 & 0.056 & 0.2680191 & 0.1620675 & 0.01876134 & 1.00 & 0.00 & 0.00 \\
Final & & & & & & & & & \\
\hline
\end{tabular}

\section{UJICOBA SISTEM}

Ketika pesawat sedang mengudara dengan ketinggian dan kecepatan yang sudah ditentukan, perlu dipastikan bahwa pesawat benar - benar dalam ketinggian dan kecepatan yang sudah ditentukan. Ketinggian dan kecepatan ketika mengudara tidak selalu sama karena faktor kecepatan angin yang berbeda-beda. Hasil realisasi kecepatan dan ketinggian seperti pada Tabel V.

- Tabel 5. Hasil Realisasi Kecepatan dan Ketinggian Pesawat

\begin{tabular}{|c|l|l|l|l|l|l|}
\hline \multirow{2}{*}{ No } & \multicolumn{2}{|c|}{ Pemrograman 100m 12m/s } & \multicolumn{2}{c|}{ Pemrograman $125 \mathrm{~m} 12 \mathrm{~m} / \mathrm{s}$} & \multicolumn{2}{c|}{ Pemrograman 150m 12m/s } \\
\cline { 2 - 7 } & Ketinggian & Kecepatan & Ketinggian & Kecepatan & Ketinggian & Kecepatan \\
\hline 1 & $102.57 \mathrm{~m}$ & $12.17 \mathrm{~m} / \mathrm{s}$ & $125.03 \mathrm{~m}$ & $12.07 \mathrm{~m} / \mathrm{s}$ & $150.61 \mathrm{~m}$ & $12.00 \mathrm{~m} / \mathrm{s}$ \\
\hline 2 & $103.01 \mathrm{~m}$ & $12.19 \mathrm{~m} / \mathrm{s}$ & $125.28 \mathrm{~m}$ & $12.74 \mathrm{~m} / \mathrm{s}$ & $149.50 \mathrm{~m}$ & $12.72 \mathrm{~m} / \mathrm{s}$ \\
\hline 3 & $99.95 \mathrm{~m}$ & $12.42 \mathrm{~m} / \mathrm{s}$ & $125.54 \mathrm{~m}$ & $13.01 \mathrm{~m} / \mathrm{s}$ & $150.75 \mathrm{~m}$ & $11.69 \mathrm{~m} / \mathrm{s}$ \\
\hline $\begin{array}{l}\text { Rata- } \\
\text { rata }\end{array}$ & $101.84 \mathrm{~m}$ & $12.26 \mathrm{~m} / \mathrm{s}$ & $125.28 \mathrm{~m}$ & $12.60 \mathrm{~m} / \mathrm{s}$ & $150.29 \mathrm{~m}$ & $12.14 \mathrm{~m} / \mathrm{s}$ \\
\hline
\end{tabular}

\section{Data Kesesuaian Lajur Terbang Pesawat}

Hasil pemrograman lajur terbang pesawat ditandai dengan garis berwarna kuning, seperti pada Gambar 10 Bentuk pesawat berwarna merah adalah posisi pesawat itu sendiri yang terbang mengikuti lajur yang sudah diprogram. Ketika pesawat sedang mengudara, maka hasil rekam jejak pesawat berupa garis ungu. Dapat dibandingkan dengan lajur ketika pesawat mengudara seperti pada Gambar 11. 


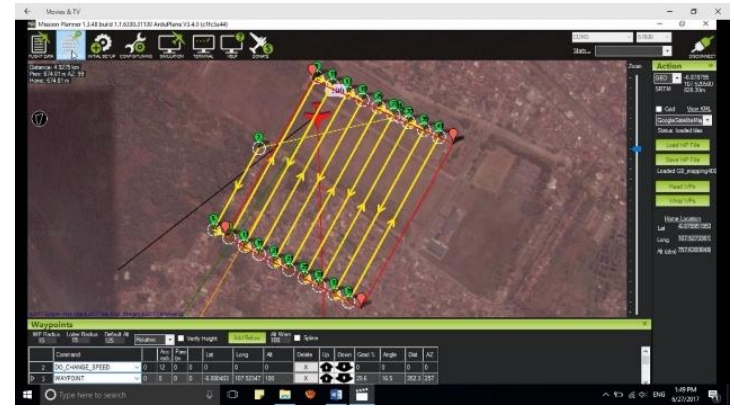

口 Gambar 10 Rencana Lajur Terbang pesawat

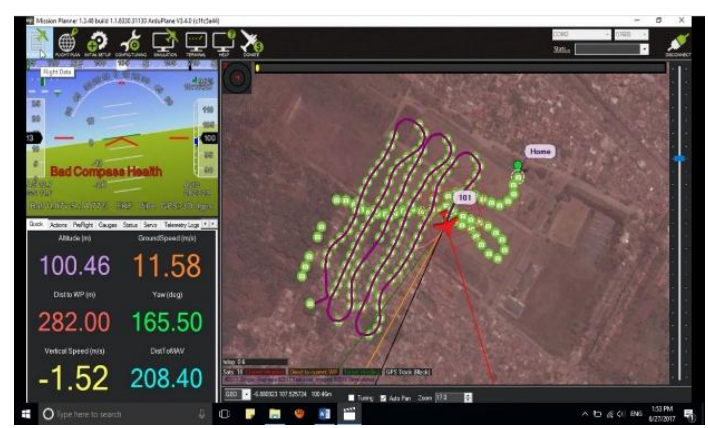

- Gambar 11 Hasil Rekam Jejak Pesawat

\section{Hasil Peta}

Pada Gambar 12 adalah hasil screenshoot dari aplikasi google earth untuk mengetahui jarak pada daerah yang sudah dipetakan. Dalam penentuan skala gambar pemetaan, dibandingkan jarak dari Google Earth dengan jarak hasil pemetaan. Berdasarkan pengamatan pada aplikasi google earth, jarak lapangan seperti yang ditandai dengan garis kuning pada Gambar 12 berjarak 80.09m.

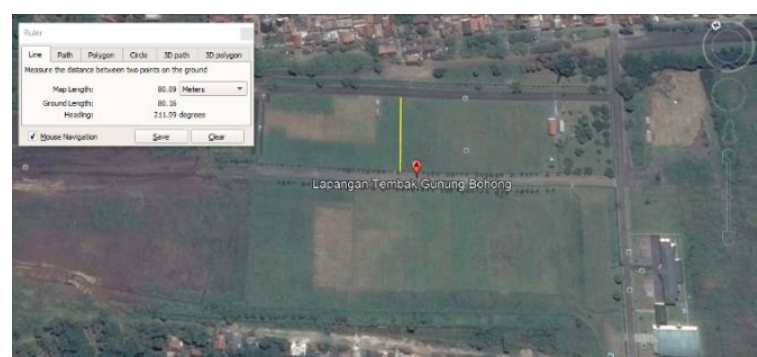

- Gambar 12 Jarak lokasi yang dipetakan dari Google Earth

Lalu pada daerah lapangan yang sama juga diukur jaraknya pada peta, maka akan didapat skala gambar. Luas area pemetaan sekitar 16 hektar yang dapat dilihat pada Gambar 13 adalah estimasi luas daerah yang dipetakan dengan menggunakan aplikasi google earth.

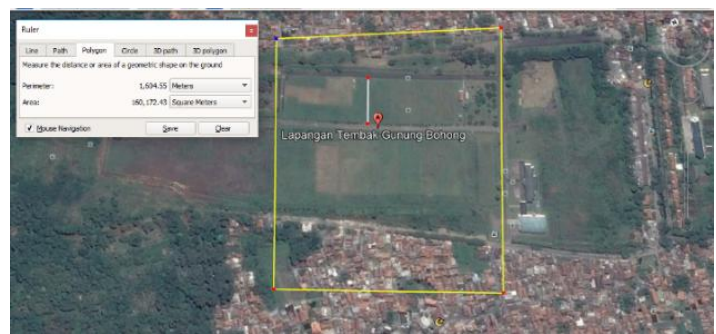

- Gambar 13 Estimasi Luas daerah pemetaan dengan Aplikasi Google Earth

Dengan kecepatan terbang 12m/s Gambar 14 menunjukkan hasil pemetaan pada ketinggian 100m, Gambar 15 adalah hasil pemetaan dengan ketinggian 125m, Gambar 16 adalah hasil pemetaan dengan ketinggian $150 \mathrm{~m}$. 


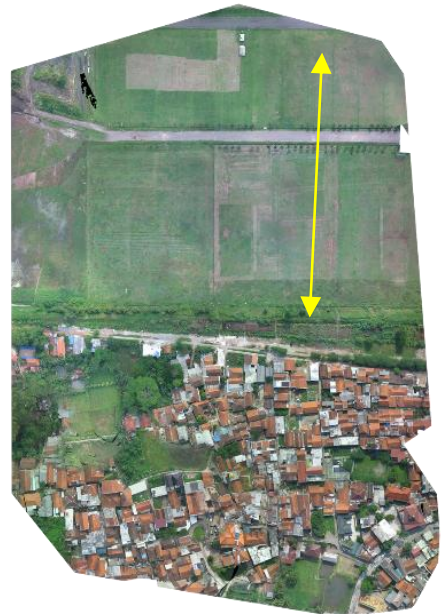

- Gambar 14 Hasil Peta dengan

Ketinggian Jelajah 100m Skala 1:28.76

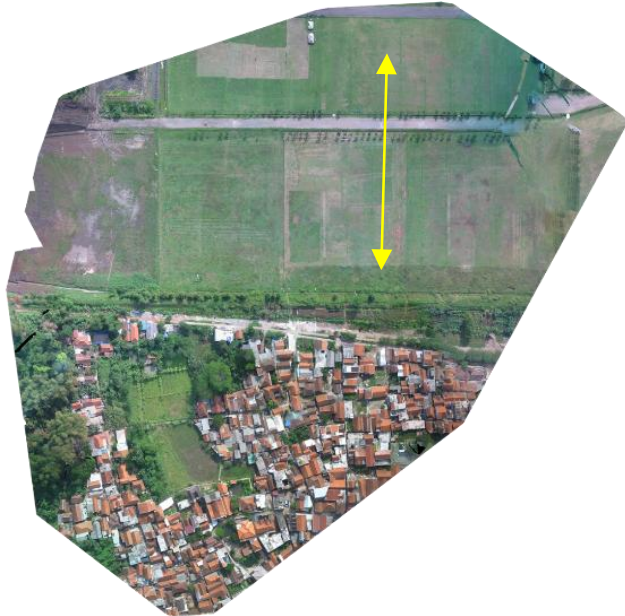

- Gambar 15 Hasil Peta dengan

Ketinggian Jelajah 125m Skala 1:38

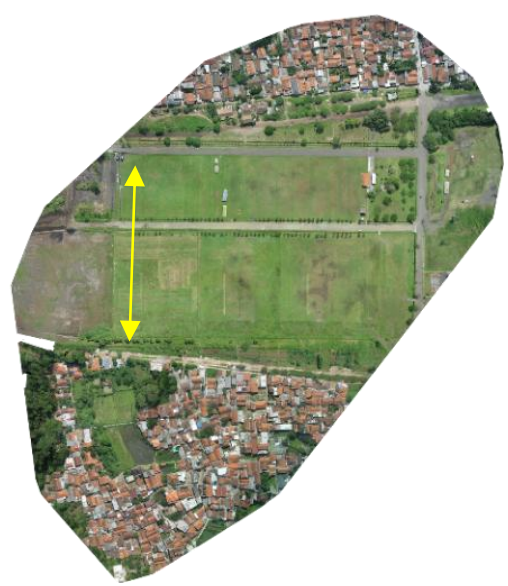

— Gambar 16 Hasil Peta dengan Ketinggian Jelajah 150m Skala 1:47

Pemetaan dilakukan dengan ketinggian pesawat yang berbeda - beda untuk mengetahui pengaruh ketinggian pemetaan dengan hasil peta. Pemetaan dilakukan dengan ketinggian 100m, 125m, 150m. Metoda untuk melihat kualitas hasil peta adalah dengan cara mengambil satu area peta yang sama dengan ukuran yang sama dan dibandingkan satu dengan yang lainnya. Berikut hasil perbandingan hasil peta seperti pada Tabel VI.

Tabel 6 Perbandingan Hasil Peta dengan Ketinggian yang Berbeda

\begin{tabular}{|l|c|l|}
\hline \multicolumn{2}{|c|}{ NO } & \multicolumn{1}{|c|}{ Hasil Peta } \\
\hline $\begin{array}{l}\text { 1. Hasil Peta } \\
\text { dengan Ketinggian } \\
100 \mathrm{~m}\end{array}$ & $\begin{array}{l}\text { Kari semua hasil peta yang } \\
\text { diambil dapat disimpulkan } \\
\text { bahwa ketinggian } \\
\text { mempengaruhi hasil kualitas } \\
\text { peta. Hasil peta terbaik adalah } \\
\text { dengan ketinggian 100m. Hasil } \\
\text { ketinggian pada 125m gambar } \\
\text { mulai sedikit buram dan pada } \\
\text { ketinggian 150m gambar }\end{array}$ \\
\hline
\end{tabular}




\begin{tabular}{|l|l|l|}
\hline $\begin{array}{l}\text { 2. Hasil Peta } \\
\text { dengan Ketinggian } \\
125 \mathrm{~m}\end{array}$ & $\begin{array}{l}\text { terlihat sangat buram dibanding } \\
\text { hasil gambar pada ketinggian } \\
125 \mathrm{~m} \text { dan 100m }\end{array}$ \\
\hline $\begin{array}{l}\text { H. Hasil Peta } \\
\text { 150m Ketinggian }\end{array}$
\end{tabular}

\section{Kesimpulan}

\section{KESIMPULAN DAN SARAN}

1. Perancangan pesawat UAV untuk pemetaan dapat berhasil direalisasikan dengan menggunakan bahan dasar polyfoam dan kayu balsa, motor electric brushless Turnigy480-850kv, flight controller, speed controller, GPS, motor servo, kamera digital, remote control, baterai lithium polymer, dan baling-baling.

2. Pesawat UAV beserta mapping system-nya berhasil memetakan wilayah berukuran $\pm 165,506 \mathrm{~m}^{2}$

3. Hasil pemetaan yang didapat berupa foto udara dari ketinggian $100 \mathrm{~m}, 125 \mathrm{~m}$, dan $150 \mathrm{~m}$. dengan kecepatan terbang $12 \mathrm{~m} / \mathrm{s}$. Hasil foto udara terbaik didapat dari pemetaan pada ketinggian $100 \mathrm{~m}$.

4. Metode penentuan nilai PID yang menghasilkan pemetaan yang terbaik adalah dengan cara autotune yang menghasilkan nilai PID Roll (P: 0.8, I: 0.056, D: 0.056), PID Pitch (P: 0.2680191, I: 0.1620675, D: 0.01876134), PID Yaw (P: 1.00, I: 0.00, D: 0.00).

\section{Saran}

Saran-saran yang dapat diberikan untuk perbaikan dan pengembangan penelitian ini adalah :

1. Diperlukan perancangan antena untuk telemetry maupun remote control agar jarak koneksi lebih jauh

2. Diperlukan kamera yang memiliki resolusi yang lebih tinggi untuk pemetaan agar hasil peta jauh lebih baik

\section{DAFTAR PUSTAKA}

[1] Ahmad, A. 2010. Aerial Mapping using High Resolution Digital Camera and Unmanned Aerial Vehicle for Geographical Information System. IEEE, 201-205.

[2] Team, A. D. 2016. jDrones. Retrieved from ardupilot: http://ardupilot.org/copter/docs/common-apm-to-chdkcamera-link-tutorial.html

[3] pix4d. 2012 - 2017. pix4d desktop user manual 3.2. Lausanne: Procab.

[4] JDrones. 2016. Setup for Plane. Retrieved from Ardupilot: http://ardupilot.org/plane/docs/arduplanesetup.html

[5] Staples, G. 2014, April. Propeller Static \& Dynamic Thrust Calculation. Retrieved from Electric RC Aircraft Guy: http://www.electricrcaircraftguy.com/2013/09/propeller-static-dynamic-thrust-equation.html

[6] Wing Loading. (n.d.). Retrieved from Common Sense RC:

https://www.commonsenserc.com/page.php?page=wing_loading.html

[7] 3D Robotics. 2013, October 16. IRIS Operation Manual. Retrieved from https://3dr.com/wpcontent/uploads/2013/10/operation-manual-compressed.pdf 